\title{
EXPERIMENTAL STUDY ON THE ONE DEGREE-OF-FREEDOM DUFFING OSCILLATOR WITH IMPACT
}

\author{
La Ngoc Tuan', Nguyen Van Du ${ }^{2}$," \\ ${ }^{1}$ Vinh University of Technology Education, Vietnam \\ ${ }^{2}$ Thai Nguyen University of Technology, TNU, Viet Nam
}

\begin{abstract}
This paper presents results on realizing experimental devices and evaluating the resonant area of an one degree-of-freedom Duffing oscillator with impacts. The actuator was developed from a mini shaker, using electro-mechanical interaction to convert electrical signal to mechanical vibration. The resonant areas were determined by Bode plots which depict relation between oscillation amplitude, phase angle and excitation frequencies. The resonant position as well as the electro-mechanical interaction were evaluated experimentally. The results showed that, impacts significantly influenced on the resonant frequency. The supplied current appeared to reduce considerably when resonance occured. The results would be promising for further studies on vibration with impact problems.
\end{abstract}

Keywords: Nonlinear dynamics, Duffing oscillator, 1-DOF, vibro-impact, resonance.

\section{NGHIÊN CÚU THỰC NGHIÊM CƠ CẤU RUNG VA ĐẬP DUFFING MỘT BẬC TỰ DO}

\author{
La Ngọc Tuấn ${ }^{1}$, Nguyễn Văn Dự ${ }^{2, *}$ \\ ${ }^{1}$ Truoòng Đại hoc Su pham Kỹ thuật Vinh, Việt Nam \\ ${ }^{2}$ Truò̀ng Đại học Kỹ thuật Công nghiệp - ĐH Thái Nguyên
}

\section{TÓM TẮT}

Bài báo này trình bày kết quả nghiên cứu thực nghiệm về triển khai thiết bị và khảo sát vùng cộng hưởng của cơ cấu rung động Duffing một bậc tự do có va đập. Cơ cấu được phát triển dựa trên một máy phát rung động nhỏ, sử dụng tương tác điện từ nhằm biến dao động của tín hiệu nguồn thành dao động của ống dây bên trong. Vùng cộng hưởng được xác định dựa trên biểu đồ Bode, phản ánh tương quan giữa biên độ dao động, góc pha giữa tín hiệu nguồn và dao động với tần số kích thích. Vị trí vùng cộng hưởng, tương tác cơ-điện được khảo sát và phân tích từ kết quả thực nghiệm. Kết quả cho thấy, va đập làm thay đổi đáng kể tần số cộng hưởng của cơ cấu. Một phát hiện hữu ích khác là cường độ dòng điện kích thích giảm đáng kể khi xuất hiện cộng hưởng. Các kết quả thu được có thể là nguồn tham khảo cho các bài toán có va đập xuất hiện kèm rung động. Từ khóa: Động lục học phi tuyến, cơ cấu Duffing, hệ một bậc tụ do, rung động-va đập, cộng huởng.

Ngày nhận bài: 26/6/2019; Ngày hoàn thiện: 11/7/2019; Ngày đăng: 12/7/2019

* Corresponding author. Email: vandu@tnut.edu.vn https://doi.org/10.34238/tnu-jst.2019.10.1749 


\section{Introduction}

The Duffing oscillator has been well-known as the ones having a mass attached to a nonlinear spring, whose restoring force is expressed in a cubic function of its elastic deformation [1]. A one-degree-of-freedom (1DOF) Duffing oscillator is described by the following differential equation:

$$
X^{\prime \prime}+\gamma X^{\prime}+\alpha X+\beta X^{3}=F \cos (\Omega t)
$$

where $\mathrm{X}$ is the oscillation amplitude, $\mathrm{X}^{\prime}$ and $X^{\prime \prime}$ are the first and second derivative of $X$, respectively. In Equation (1), the nonlinear term $\beta X^{3}$ changes the dynamics of the system harshly and make it difficulties in finding exact solutions such as [2]:

- An analytic solution is no longer available;

- The superposition principle is no longer valid.

In practices, The Duffing equation is usually used to describe many nonlinear systems. Because all practical springs exhibit a nonlinear force-deflection relation, the Duffing model with nonlinear spring force would be more accurate in applications. In addition to the nonlinear cubic term, a Duffing oscillator with impacts exhibit a stronger nonlinear and thus much richer mechanic behaviors.

Previously, several investigations have been paid to the Duffing oscillator with impacts. For example, a theoretical study of Avramova and Borysiuk [3] employing a nonsmooth unfolding transformation to analyze the dynamics of a one-degree-of-freedom impact Duffing oscillator. The stochastic bifurcations and response of vibro-impact Duffing-Van der Pol oscillators, subjected to white noise were examined in several studies [4], [5], [6]. It has been found that most studies focused on the fundamental behavior of the system. A vibro-impact Duffing model using minishaker, proposed for drifting systems [7] has been found as a practical application as well as an experimental study in this trend. For simpler oscillators with linear spring force, the interaction between electro-magnetic and mechanical forces during impact and drifting in a similar device was also carried out [8]. The phase lag between the magnetic excitation force and the motion of the impact mass has been identified as a control factor to obtain maximum progression rate of such machines [9]. In order to make the device more practical applicable, this paper experimentally identifies major parameters of such vibro-impact device but with the cubic spring force in its resonance area. The results would play important basic for further studies of applying this device in practice.

This paper is organized as follows: Section 2 portrays the design and implementation of the system. In Section 3, the experimental results are reported and discussed. Several important remarks are concluded in Section 4.

\section{Experimental implementation}

The experimental setup was designed based on the common principle of the 1-DOF system with impact. Figure 1 depicts the realized setup. A mini electro-dynamical shaker (1) was used to generate the required harmonic oscillation. The shaker is fixed on a steel and heavy table via screws (2). The movable coil (3) of the shaker is supported by a shaft which is placed on a couple of leaf springs (4). Given that the shaker body is fixed, supplying a sinusoidal current to the shaker coil leads to oscillations of the shaft.

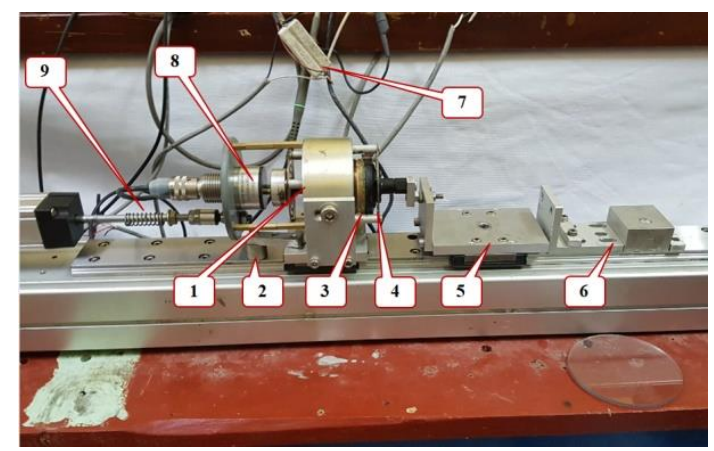

Figure 1. The experimental setup

A mass (5) is joined and thus can oscillate together with the shaft. The mass is placed on a rolling slider of a rail guide to minimize the frictional force when moving. An obstacle 
block (6) was fixed nearby the car oscillation path to obtain impact force.

The shaker was powered by a sinusoidal signal which was amplified by a commercial amplifier with a fixed gain. Two levels of the voltage supplied to the shaker were obtained by two levels of the control signals at $150 \mathrm{mV}$ and $200 \mathrm{mV}$. The voltage signal drop on a resistor (7) was used to measure the current supplying to the shaker. Relative displacement between the mass (5) and the shaker body was measured by means of a noncontact displacement sensor (8) model KD-2306 from Kaman Precision Products. A linear variable displacement transducer (LVDT) (9) is preserved to measure the body shaker movement in the further study for 2 DOF systems.

At the first step, the spring force depending on the displacement was measured as below. The mass 5 was pushed to slowly move along the rail guide by mean of a transmission screw. The pushing force was collected by a load cell placed between the screw and the mass. Experimental data of the force with respect to the displacement were then plotted.

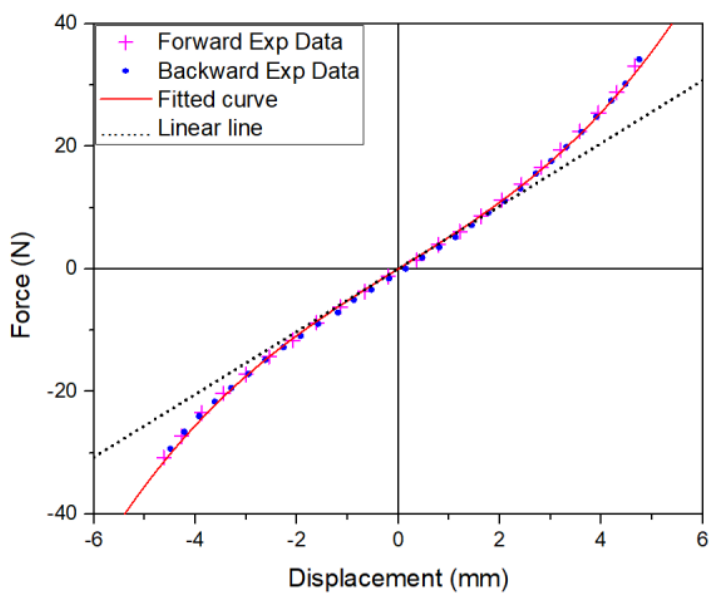

Figure 2. Function fitting of spring force with respect to displacement (solid) and a reference linear line (dot)

A nonlinear regression in the cubic form was then applied to carry out the spring force as a function of the displacement. Figure 2 presents the nonlinear fitting results. A linear spring function having the stiffness as same as the linear term in the fitted cubic function was plotted for reference. Details of fitting function is depicted in Table 1.

Table 1. Fitted result of the spring function

\begin{tabular}{r|l}
\hline \hline Model & Duffing (User) \\
Equation & $\mathrm{k} 1 * \mathrm{X}+\mathrm{k} 2 * \mathrm{X}^{\wedge} 3$ \\
Plot & Spring force \\
$\mathrm{k} 1(\mathrm{~N} / \mathrm{mm})$ & 5.12365 \\
$\mathrm{k} 2(\mathrm{~N} / \mathrm{mm})$ & $7.89 \mathrm{E}-02$ \\
Reduced Chi-Sqr & 0.27622 \\
R-Square(COD) & 0.99909 \\
Adj. R-Square & 0.99909 \\
\hline \hline
\end{tabular}

As can be seen in Table 1, with the R-square factor of 0.99909 , the spring force function can be expressed as:

$$
F_{s p r}=5.12365 X+0.0789 X^{3}
$$

The spring force, which was well fitted in a cubic function, exhibited that the device is in fact a Duffing oscillator. From Equation (2) the sign of the cubic term is positive, as well as referring to the reference linear function in Figure 2, it can be observed that the investigated system is a hardening spring Duffing oscillator [10].

In the next section, several important results of experimental tests are presented. The main purpose of the tests is to prepare essential basics for further studies on 2 DOF vibroimpact systems, as described below.

- To validate an important character of a nonlinear system is that the dependence of the resonance frequency on the level of excitation force;

- To carry out how the excitation force changes when the system falls in the resonant situation;

- To point out if the phase lag between excitation and displacement of the mass in resonant stage follows the rule found in [9] in impact stage. 


\section{Results and discussions}

\subsection{Resonant frequency}

For typical oscillators, the frequencies at which the response amplitude is a relative maximum are known as resonant frequencies. In adjacent areas of such resonant frequencies, small periodic forces would produce large amplitude oscillations, due to the storage of vibrational energy.

In nonlinear systems, the maximum response does not occur close to the system natural frequency as usually appears in linear systems. The Duffing oscillator, with the appearance of the cubic nonlinearity, has been well known as a classical model for remarkable jump phenomenon, as illustrated in Figure 3 [11].

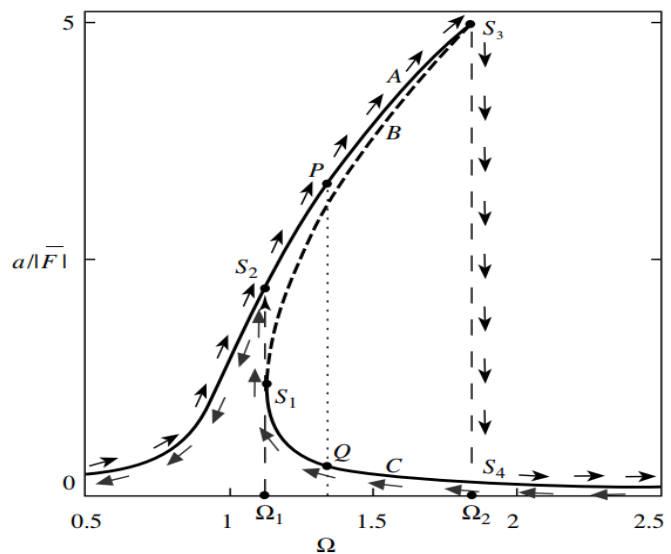

Figure 3. Typical response of a Duffing oscillator [11]

As can ben seen in Figure 3, the maximum oscillation amplitude (the response) of the system would be either $S_{2}$ or $S_{3}$, depending on the direction of the frequency changes. If the excitation frequency progressively increases, a maximum response (i.e. a resonance) $\mathrm{S}_{3}$ would occur when the excitation frequency reaches the value of $\Omega_{2}$, and then suddenly jumps down. In constrast, if the excitation frequency gradually decreases, the oscillation amplitude would slowly increases and reaches $\mathrm{S}_{2}$ at the frequency of $\Omega_{1}$. This special character is the most difference to linear systems.
It would be worth noting that the full response curve shown in Figure 3 is not able to obtain experimentally. There only points on the two parts of the curve (shown in solid line) can be collected. Besides, experimental setup both to control the excitation frequency and to capture the system response is usually complicated and required expensive harwares and licensed softwares. This study presents a simple practical approach to implement the required functions to evaluate the system response.

A digital oscilloscope model PicoScope 2204A, a cost-saving equipment, was used to generate progressively changes of excitation frequency. The genertaed signal was then supply to the shaker via commercial amplifier. At each value of the excitation frequency, the proportion of the mass displacement of the mass to the excitation force was calculated. The oscillation amplitude was measured by the sensor (8), as mentioned in Section 2, and was assigned as the output voltage, $\mathrm{V}_{2}$. The excitation force was determined by the current passing the shaker and assigned as the input voltage, $\mathrm{V}_{1}$. Consequently, the proportion ratios of the mass displacement of the mass to the excitation force was carried out in the unit of Decibel $(\mathrm{dB})$ as following equation:

$$
R=20 \log \left(\frac{V_{2}}{V_{1}}\right)
$$

The approach mentioned was easy to be implemented by mean of the Bode plot function in the software named Frequency Response Analyzer for PicoScope (FRA4PS), which is avalable and free of charge.

The data collected were then used to draw curves of the output-input ratio as a function of the excitation frequency. Resonant points are the ones where the curves reached maximum values. 
Figure 4 depicts two cases of different levels of the supplied voltages. As can be seen in the figure, increasing frequency resulted in higher resonant frequencies. For example, with a lower voltage supply $\left(\mathrm{V}_{\mathrm{exc}}=150 \mathrm{mV}\right)$, the resonance occured at $18.957 \mathrm{~Hz}$ in the case of increasing frequency and at $18.451 \mathrm{~Hz}$ when decreasing frequency. Similarly, with the control signal of $200 \mathrm{mV}$, the increasing and decreasing directions of excitation

(a)

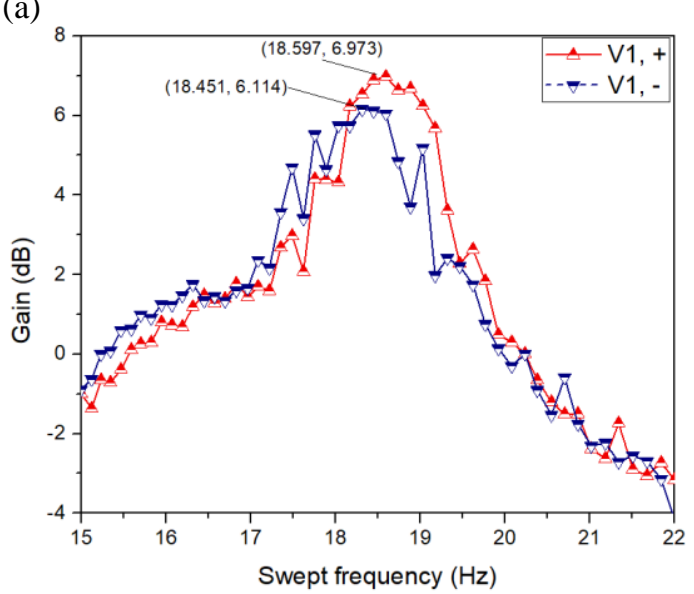

frequencies provided resonances at $19.303 \mathrm{~Hz}$ and $18.472 \mathrm{~Hz}$, respectively. From these results, it would be verified that the proposed experimental appoach is validated and thus can be used to further evaluate the system behavior in case of vibro-impact situations.

Applying the similar approach for the system attaching the obstacle block, i.e. the vibroimpact system, the experimental frequency response curves are depicted in Figure 5. (b)

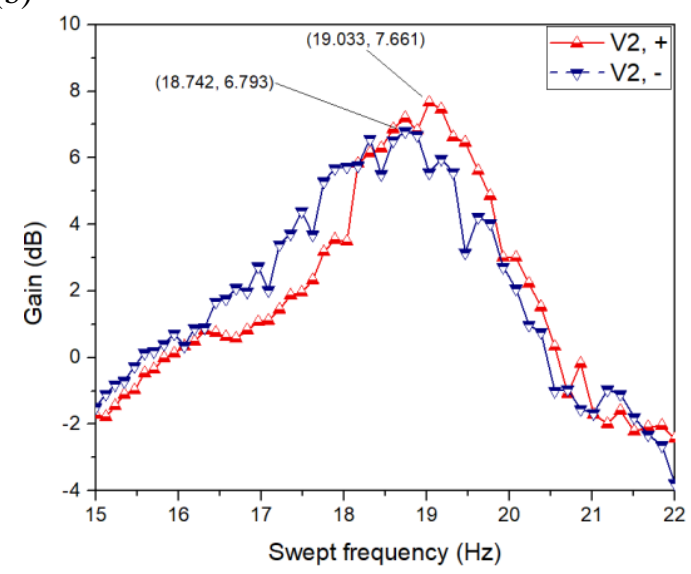

Figure 4. Frequency response of forced, 1 DOF vibration system when increasing (lines with upside diamond symbols) and decreasing (lines with downside diamond symbols), the control signal levels of: a) $150 \mathrm{mV}$ and b) $200 \mathrm{mV}$

(a)

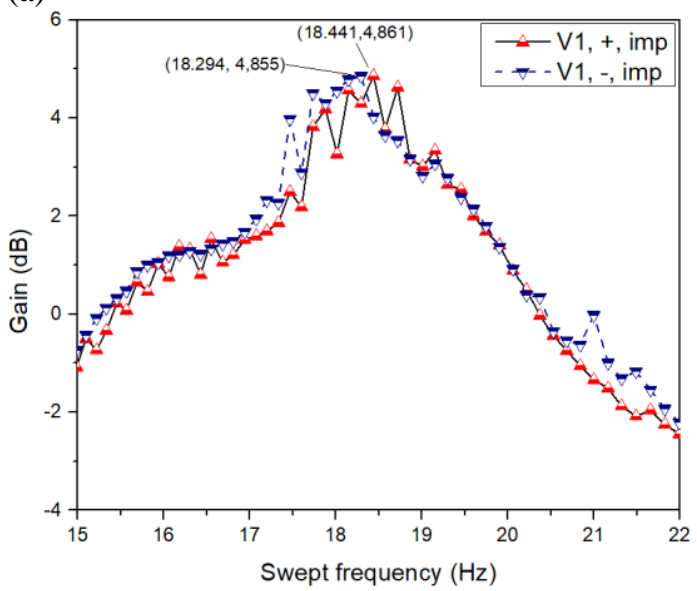

(b)

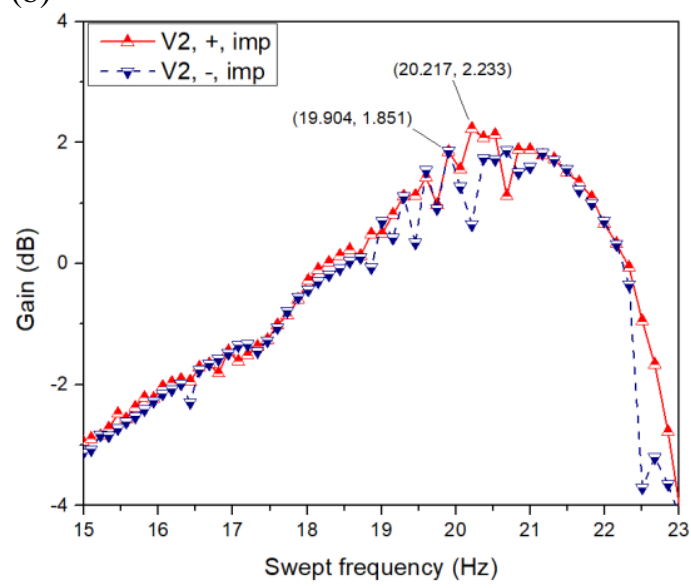

Figure 5. Frequency response of forced, 1 DOF vibro-impact system when increasing (lines with upside diamond symbols) and decreasing (lines with downside diamond symbols), the control signal levels of: a) $150 \mathrm{mV}$ and b) $200 \mathrm{mV}$ 
It can be observed from Figure 5 that, as similar to that of the free vibration, higher excitation power also resulted in higher resonant frequencies. At the same power supply, the resonant frequency when increasing control frequency is higher than that decreasing control frequency. Another important point is that, with the same level of the power supplied, the resonant frequency in vibro-impact stage is higher than that in free vibration. This observation would play an important basic for further study on vibroimpact dynamic responses.

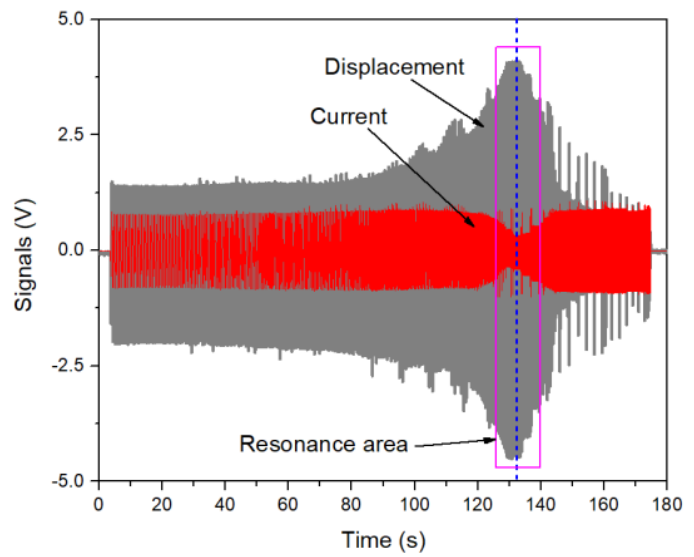

\subsection{Electro-mechanical interaction}

The interactions between power supply and the dynamical behavior of the vibro-impact actuator have been rarely found in literature. In order to carry out the coupled interaction between such stages, as previously implemented [8], signals of the current passing the shaker and displacement of the mass in both situations of free vibration and impact were collected. Figure 6 presents two illustrations from the two situations: free vibration (Figure 6a) and vibro-impact (Figure 6b).

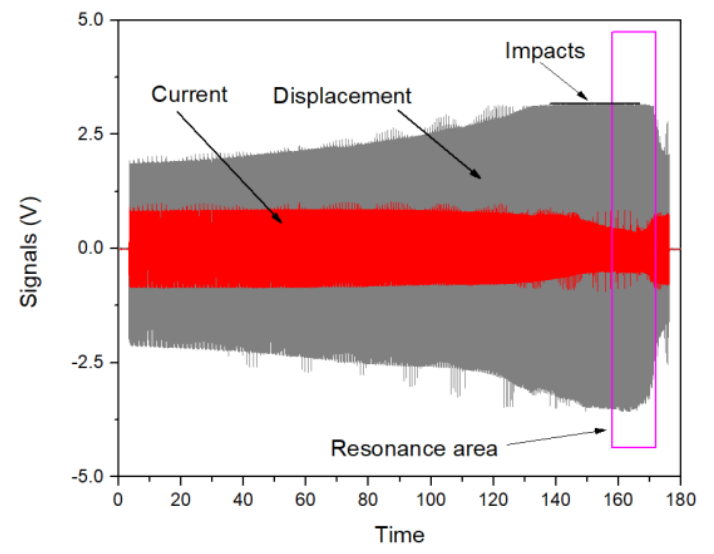

Figure 6. (Color online) Time histories of the displacement of the mass (grey) and the current supplied (red) for: a) free vibration and b) vibro-impact. Resonant area are marked by magenta retangles

As can be seen in Figure 6, the current supplying to the shaker was significantly reduced when resonance occurred. Such phenomena were not only appeared in free vibration (Figure 6a) but also in the situation of vibration combined with impact (Figure 6b). This observation would be very promising for further optimization of the device regarding energy saving purpose.

\subsection{Phase lag in resonant stage}

The phase lag between power supply and the actuator displacement has been found to be an effective parameter to control the system obtaining optimized progress rate [9].

Consequently, this study initially validate if the phase lag in resonant stage satisfied the condition proposed in [9]. For this reason, signals of the supplied current and of the mass displacement were collected and analyzed.
Figure 7 presents relations between the two signals when the resonance occurred in both situations: free vibration (Figure 7a) and vibro-impact (Figure 7b).

As can be seen in the Figure $7 \mathrm{a}$, the current signal appeared to go ahead of the mass displacement an approximate angle of $\pi / 2$. In impact stage (Figure 7b), the time when the current signal switched from a positive to a negative sign appeared after the instant when the mass collided with the stop. This observation seemed to agree with the experimental results obtained in [9]. It would make confident that, the best situation of progression rate of a 2 DOF can also developed from the stage of resonant situation of such device. The results obtained in this study thus would provide a good basic for further study on 2 DOF systems using Duffing oscillators. 
(a)

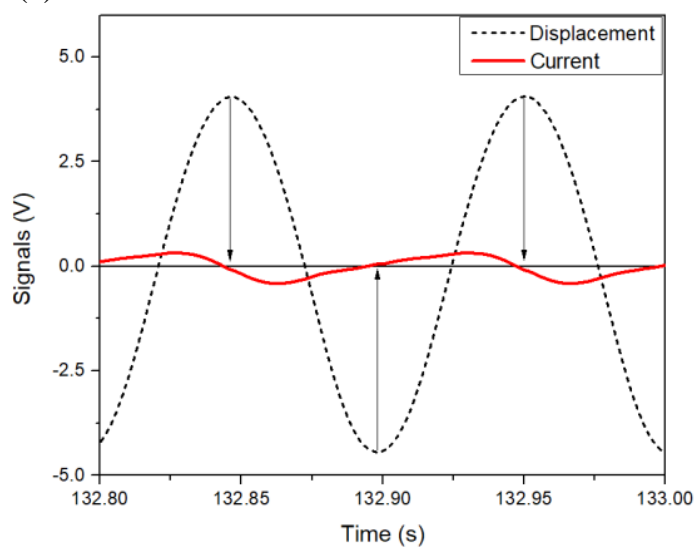

(b)

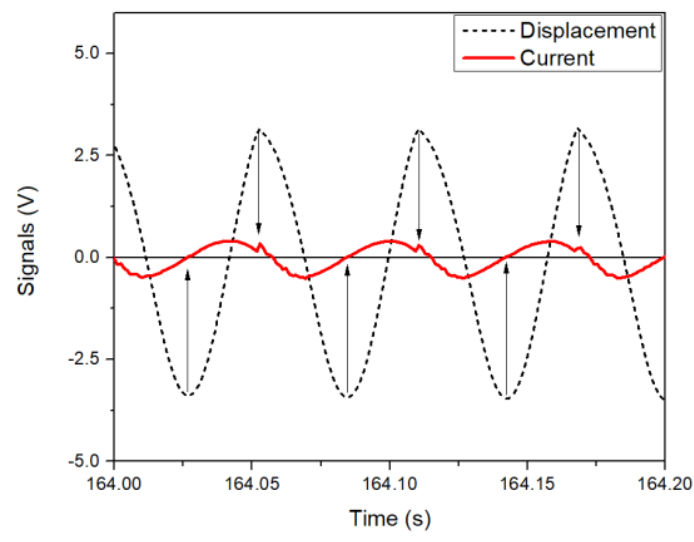

Figure 7. A close-up of time histories at the resonant stage of the displacement of the mass (dots) and the current supplied (solid line) for: a) free vibration and b) vibro-impact

\section{Conclusion}

The experimental results presented in this paper were obtained from collected data on a practical one DOF Duffing oscillator. The valuable remarks can be concluded as below.

1) An experimental device of Duffing oscillator which is able to collect reliable data can be obtained from available and costsaving hardware and software. The system and experimental observation at 1-DOF stage can be further employed for 2-DOF systems.

2) The resonant frequency in vibro-impact stage is higher than that in free vibration;

3) When resonance occurred, the current supplied to the electro-actuator significantly reduced, promising a further study on saving energy for such devices.

4) The phase lag between current supplied and the mass displacement in the resonant stage appeared similarly to that in the best situation of 2-DOF systems. Phase lag would be a good control parameter to obtain a desired situation.

\section{Acknowledgements}

This research is funded by Vietnam National Foundation for Science and Technology Development (NAFOSTED) under grant number 107.01-2017.318.

\section{REFERENCES}

[1]. Ivana Kovacic and Michael Brennan, The Duffing Equation: Nonlinear Oscillators and their Behaviour, Wiley publisher, 2011.

[2]. Hans Jürgen Korsch, Hans-Jörg Jodl, and Timo Hartmann, "The Duffing Oscillator," in Chaos, pp. 157-184, Springer Berlin Heidelberg, 2008.

[3]. K. V. Avramov and O. V. Borysiuk, "Analysis of an impact Duffing oscillator by means of a nonsmooth unfolding transformation," Journal of Sound and Vibration, vol. 318, pp. 1197-1209, 2008.

[4]. P. Kumar, Narayanan, and S. S. \& Gupta, "Stochastic bifurcations in a vibro-impact Duffing-Van der Pol oscillator," Nonlinear Dynamics, vol. 85, pp. 439, 2016.

[5]. Guidong Yang, Wei Xu, Xudong Gu, and Dongmei Huang, "Response analysis for a vibroimpact Duffing system with bilateral barriers under external and parametric Gaussian white noises," Chaos, Solitons \& Fractals, vol. 87, pp. 125-135, 2016.

[6]. Jinqian Feng, Wei Xu, Haiwu Rong, and Rui Wang, "Stochastic responses of Duffing-Van der Pol vibro-impact system under additive and multiplicative random excitations," International Journal of Non-Linear Mechanics, vol. 44, pp. 51-57, 2009.

[7]. Van-Du Nguyen, The-Hung Duong, NgocHung Chu, and Quoc-Huy Ngo, "The effect of inertial mass and excitation frequency on a Duffing vibro-impact drifting system," International Journal of Mechanical Sciences, vol. 124-125, pp. 9-21, 2017.

[8]. Van-Du Nguyen, Huu-Cong Nguyen, NhuKhoa Ngo, and Ngoc-Tuan La, "A New 
Design of Horizontal Electro-Vibro-Impact Devices," Journal of Computational and Nonlinear Dynamics, vol. 12, pp. 061002061011, 2017.

[9]. Van-Du Nguyen, Huu-Duc Ho, The-Hung Duong, Ngoc-Hung Chu, and Quoc-Huy Ngo, "Identification of the Effective Control Parameter to Enhance the Progression Rate of Vibro-Impact Devices With Drift," Journal of Vibration and Acoustics, vol. 140, pp. 011001, 2017.
[10]. Michael J. Brennan and Ivana Kovacic, "Examples of Physical Systems Described by the Duffing Equation," in The Duffing Equation, Wiley publisher, 2011.

[11]. Tamás Kalmár-Nagy and Balakumar Balachandran, "Forced Harmonic Vibration of a Duffing Oscillator with Linear Viscous Damping," in The Duffing Equation, Wiley publisher, 2011. 